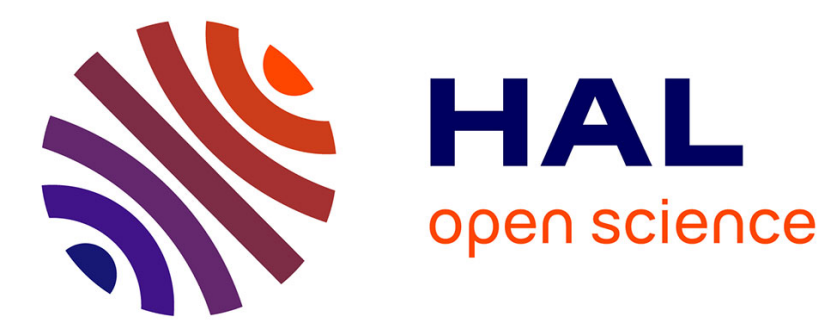

\title{
Inhibition of epidermal growth factor receptor over-expressing cancer cells by the aphorphine-type isoquinoline alkaloid, dicentrine
}

\author{
V. Badireenath Konkimalla, Thomas Efferth
}

\section{- To cite this version:}

V. Badireenath Konkimalla, Thomas Efferth. Inhibition of epidermal growth factor receptor overexpressing cancer cells by the aphorphine-type isoquinoline alkaloid, dicentrine. Biochemical Pharmacology, 2010, 79 (8), pp.1092. 10.1016/j.bcp.2009.11.025 . hal-00565097

\section{HAL Id: hal-00565097 \\ https://hal.science/hal-00565097}

Submitted on 11 Feb 2011

HAL is a multi-disciplinary open access archive for the deposit and dissemination of scientific research documents, whether they are published or not. The documents may come from teaching and research institutions in France or abroad, or from public or private research centers.
L'archive ouverte pluridisciplinaire HAL, est destinée au dépôt et à la diffusion de documents scientifiques de niveau recherche, publiés ou non, émanant des établissements d'enseignement et de recherche français ou étrangers, des laboratoires publics ou privés. 


\section{Accepted Manuscript}

Title: Inhibition of epidermal growth factor receptor over-expressing cancer cells by the aphorphine-type isoquinoline alkaloid, dicentrine

Authors: V. Badireenath Konkimalla, Thomas Efferth

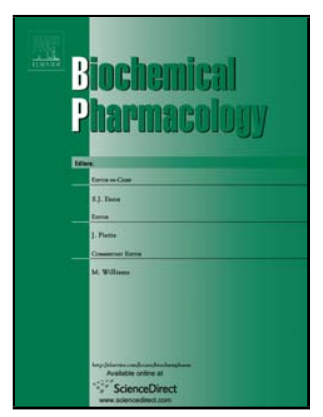

PII:

S0006-2952(09)01064-8

DOI:

doi:10.1016/j.bcp.2009.11.025

Reference:

BCP 10403

To appear in: $\quad B C P$

Received date: $\quad 21-10-2009$

Revised date: 27-11-2009

Accepted date: $\quad 30-11-2009$

Please cite this article as: Konkimalla VB, Efferth T, Inhibition of epidermal growth factor receptor over-expressing cancer cells by the aphorphinetype isoquinoline alkaloid, dicentrine, Biochemical Pharmacology (2008), doi:10.1016/j.bcp.2009.11.025

This is a PDF file of an unedited manuscript that has been accepted for publication. As a service to our customers we are providing this early version of the manuscript. The manuscript will undergo copyediting, typesetting, and review of the resulting proof before it is published in its final form. Please note that during the production process errors may be discovered which could affect the content, and all legal disclaimers that apply to the journal pertain. 
Inhibition of epidermal growth factor receptor over-expressing cancer cells by the aphorphine-type isoquinoline alkaloid, dicentrine

\author{
V. Badireenath Konkimalla ${ }^{1}$ and Thomas Efferth ${ }^{1} *$
}

${ }^{1}$ German Cancer Research Center, Pharmaceutical Biology (C015), Heidelberg, Germany

* Corresponding Address:

Prof. Dr. Thomas Efferth

Department of Pharmaceutical Biology,

Institute of Pharmacy,

University of Mainz

Staudingerweg 5

55099 Mainz

Germany

Tel: 49-6131-39-25751

Fax: 49-6131-39-23752

E-mail: efferth@uni-mainz.de

Running title: Inhibition of EGFR by dicentrine

Key words: microarrays, natural product, oncogenes, pharmacology, pharmacogenomics, pharmacognosy, signal transduction, systems biology 


\begin{abstract}
The extraordinary relevance of EGFR in tumour biology makes it an exquisite molecular target for tumor therapy. Despite considerable success with these EGFR tyrosine kinase inhibitors in cancer therapy, resistance against these chemical compounds develops owing to the selection of point-mutated variants of EGFR. Therefore, there is an urgent need for the identification of novel EGFR tyrosine kinase inhibitors for treating tumours caused by such EGFR mutants. We found a preferential cytotoxicity of dicentrine towards U87MG. $\mathrm{EGFR}$ transduced with a constitutively deletion-activated EGFR expression vector as compared to non-transduced wild-type U87MG cells. As determined by microarray-based mRNA expression profiling, this preferential cytotoxicity was accompanied with an activation of BRCA1-mediated DNA damage response, p53 signalling, G1/S and G2/M cell cycle regulation, and aryl hydrocarbon receptor pathways. The activation of these signalling routes might be explained by the fact that dicentrine intercalates DNA and induces DNA strand break by inhibition of DNA topoisomerases. The cell cycle might be arrested by dicentrineinduced DNA lesions.
\end{abstract}




\section{Introduction}

During the past three decades, the members of the epidermal growth factor receptor (EGFR) gene family evolved in cancer biology as important factors affecting prognosis of cancer patients [1-3]. The EGFR family consists of four members (HER1-HER4), which of HER1 (EGFR, erbB1) and HER2 (erbB2, c-neu) are best characterized. They represent a class of glycoproteins, which serve as receptors for EGF and other ligands. They activate signal transduction pathways involved in basic biological processes, such as cell proliferation, apoptosis, metastasis, and angiogenesis. HER1 and HER2 are frequently over-expressed in tumours and are associated with unfavourable prognosis [4].

EGFR molecules are inactive monomers that are activated by binding of specific ligands (e.g., EGF and TGF- $\alpha$ ). Activation is associated with either homodimerisation with a second EGFR molecule or with another HER member (i.e., HER2). The dimerisation stimulates the intrinsic tyrosine kinase activity of EGFR, which regulates specific signal transduction cascades. Constitutive EGFR activation as a consequence of mutations or gene amplification causes deregulated cellular processes, such as proliferation, invasion, angiogenesis, cell motility, cell adhesion, inhibition of apoptosis, and DNA synthesis. The kinase activity is also associated with autophosphorylation of five tyrosine residues in the Cterminal EGFR domain. Mutations affecting EGFR expression foster carcinogenesis.

The extraordinary relevance of EGFR in tumour biology makes it an exquisite molecular target for tumour therapy. Apart from therapeutic antibodies, several small molecules have been developed as EGFR inhibitors [5]. For example, gefitinib (Iressa ${ }^{\circledR}$, Astra Zeneca, DE, USA) and erlotinib (Tarveca ${ }^{\circledR}$, Genentech Inc., CA, USA) are used for the treatment of non-small cell lung cancer and other tumour types [6]. Both compounds belong to the class of quinazolinamines and exhibit their inhibitory activity on EGFR tyrosine kinases by competing with ATP for the ATP-binding pocket.

Despite considerable success with these EGFR tyrosine kinase inhibitors,,resistance develops owing to the selection of point-mutated variants of EGFR [7]. Therefore, there is an urgent need for the identification of novel EGFR tyrosine kinase inhibitors for treating tumours caused by such EGFR mutants.

Dicentrine is an aporphine-type isoquinoline alkaloid isolated from several medicinal plants, some of which have been used in traditional medicines to treat cancers and other diseases [8-15]. Dicentrine has been shown to exert cytotoxic activity towards cancer cells in vitro and in vivo [16-18]. Dicentrine binds to and intercalate DNA and inhibits the catalytic activity of DNA topoisomerases $[19,20]$. Recently, we found that dicentrine binds with high 
affinity to the erlotinib pharmacophore of EGFR by means of an in silico modelling and virtual screening approach [2]. This indicates that EGFR and related signalling pathways may play a role in mediating dicentrine's cytotoxic activity towards cancer cells.

The aim of the present investigation was to investigate, whether dicentrine may exert preferential cytotoxicity towards cancer cells over-expressing EGFR. To this end, we determined the cytotoxicity of dicentrine in non-transduced human U87MG glioblastoma cells and U87MG cells transduced with expression vectors harbouring either wild-type EGFR (U87MG.wtEGFR), deletion-activated EGFR (U87MG.AEGFR), or EGFR with a point mutation in the tyrosine kinase domain (U87MG.PK). Furthermore, transcriptome-wide mRNA expression profiling of these cell lines with and without dicentrine treatment has been performed to elucidate signalling pathways involved in the cytotoxicity of dicentrine in transduced and non-transduced cell lines. Interestingly, a connection of BRCA1-mediated DNA damage response and other DNA damage response pathways has been unravelled, indicating a relationship of EGFR and DNA damage signalling upon challenge of cancer cells with dicentrine.

\section{Material and Methods}

Drugs: Dicentrine was kindly provided by the Drug Synthesis and Chemistry Branch, Chemotherapeutic Agents Repository, National Cancer Institute, U.S.A. The chemical structure of dicentrine is shown in Supplementary Figure 1.

Cell lines: The establishment of the parental human glioblastoma cell line, U87MG and its derivatives, which over-express exogenous wild-type EGFR (U87MG.wtEGFR-2N), tyrosine kinase-deficient EGFR (U87MG.DK-2N), or constitutively active EGFR with a genomic deletion of exons 2-7 (U87MG. $\mathrm{EGGR}$ ) has been described elsewhere [21]. The cell lines were kindly provided by Dr. W.K. Cavenee (Ludwig Institute for Cancer Research, San Diego, CA, USA). Cell culture conditions of these cell lines were as described [22].

XTT proliferation assay: The toxicity of compounds was determined by means of the Cell Proliferation Kit II (Roche Diagnostics, Mannheim, Germany). This test is based on the cleavage of the yellow 2,3-bis[2-methoxy-4-nitro-5-sulfophenyl]-2H-tetrazolium-5carboxanilide inner salt (XTT) by ubiquitous dehydrogenases leading to the formation of an orange formazan dye. [23]. The amount of dye is commensurate to the number of metabolic active cells. Fresh stock solutions of each compound were prepared in DMSO at a 
concentration of $100 \mathrm{mM}$. A dilution series ranging from $10^{-9} \mathrm{M}$ to $10^{-3} \mathrm{M}$ was prepared using DMEM medium to perform the XTT test. Cells were diluted to a final concentration of $1 \times 10^{5}$ cells/mL. One hundred micro-litres of the cell suspension were sowed into the wells of a 96well culture plate (Costar, Corning, USA). Marginal wells were filled with $100 \mu \mathrm{L}$ of pure medium, in order to minimize effects of evaporation. Besides, wells filled with medium were required to determine the background absorbance caused by non-metabolized XTT. A row of wells containing cells was left untreated, and another row of wells containing cells was treated with $1 \mu \mathrm{L}$ DMSO. This served as solvent control. The other rows of wells containing cells were supplemented with different concentrations of compound. Each concentration was tested in at least two independent plates containing different batches of cells.

After incubation with compounds at $37^{\circ} \mathrm{C}, 5 \% \mathrm{CO}_{2}$ in humidified atmosphere, XTT reagent was freshly prepared and added to each well as specified by the manufacturer: XTTlabelling reagent and electron-coupling reagent were mixed in a ratio of $50: 1$, and $50 \mu \mathrm{L}$ of this mixture were added to each well of the 96-well plate. The plates were incubated for about $3 \mathrm{~h}$ at $37{ }^{\circ} \mathrm{C}, 5 \% \mathrm{CO}_{2}$ in humidified atmosphere and read out after incubation. Quantification of cell cytotoxicity was performed in an ELISA plate reader (Bio-Rad, München, Germany) at $490 \mathrm{~nm}$ with a reference wavelength of $655 \mathrm{~nm}$. Absorbance values at both wavelengths were subtracted. The cytotoxic effect of the treatment was determined as percentage of viability and compared to untreated cells [24]. The toxicity of compounds was determined by means of the formula

$$
\text { Cell viability }[\%]=\frac{\text { Absorbance of sample cells }}{\text { Absorbance of untreated cells }} \times 100 \text {. }
$$

Implemented in the simple ligand binding module of Sigma plot software (version 10.0).

RNA isolation: Total RNA of EGFR-transduced and non-transduced U87MG human glioblastoma cells was extracted from the test samples using RNeasy ${ }^{\circledR}$ Mini Kit (Qiagen Inc., Valencia, CA, USA) according to the manufacturer's instructions to obtain highly pure RNA. Isolated total RNA was re-suspended in sample buffer provided by the manufacturer. The concentration and quality of total RNA was verified by electrophoresis using the total RNA Nano chip assay on an Agilent 2100 Bioanalyzer (Agilent Technologies GmbH, Berlin, Germany). Only samples with RNA index values greater than 8.5 were selected for expression profiling. RNA concentrations were determined using the NanoDrop spectrophotometer (NanoDrop Technologies, Wilmington, DE). All of the RNA samples were stored at $-80{ }^{\circ} \mathrm{C}$ until used for microarray analyses. 
Probe labelling and Illumina Sentrix BeadChip array hybridization: Biotin-labelled cRNA samples for hybridisation on Illumina Mouse Sentrix-8 BeadChip arrays (Illumina Inc., San Diego, CA, USA) were prepared according to Illumina's recommended sample labelling procedure based on a previously published protocol [24, 25]. In brief, $250 \mathrm{ng}$ total RNA were used for complementary DNA (cDNA) synthesis, followed by an amplification/labelling step (in vitro transcription) to synthesize biotin-labelled cRNA according to the MessageAmpII aRNA Amplification kit (Ambion, Inc., Austin, TX). Biotin-16-UTP was purchased from Roche Applied Science, Penzberg, Germany. The cRNA was column purified according to TotalPrep RNA Amplification Kit, and eluted in $60 \mu \mathrm{L}$ of water. Quality of cRNA was controlled using the RNA Nano Chip Assay on an Agilent 2100 Bioanalyzer and spectrophotometrically quantified (NanoDrop).

Hybridization was performed at $58{ }^{\circ} \mathrm{C}$, in GEX-HCB buffer (Illumina Inc.) at a concentration of $50 \mathrm{ng} \mathrm{cRNA} / \mu \mathrm{L}$, unsealed in a wet chamber for $20 \mathrm{~h}$. Spike-in controls for low, medium and highly abundant RNAs were added, as well as mismatch control and biotinylation control oligonucleotides. Microarrays were washed twice in E1BC buffer (Illumina Inc.) at room temperature for $5 \mathrm{~min}$. After blocking for $5 \mathrm{~min}$ in $4 \mathrm{~mL}$ of $1 \%$ (wt/vol) Blocker Casein in phosphate buffered saline Hammarsten grade (Pierce Biotechnology, Inc., Rockford, IL), array signals are developed by a 10 min incubation in 2 $\mathrm{mL}$ of $1 \mu \mathrm{g} / \mathrm{mL}$ Cy3-streptavidin (Amersham Biosciences, Buckinghamshire, UK) solution and $1 \%$ blocking solution. After a final wash in E1BC, the arrays are dried and scanned.

Scanning and data analysis: Microarray scanning was done using a bead station array scanner, setting adjusted to a scaling factor of 1 and PMT settings at 430. Data extraction was done for all beads individually, and outliers are removed when >2.5 MAD (median absolute deviation). All remaining data points were used for the calculation of the mean average signal for a given probe, and standard deviation for each probe was calculated.

Data analysis was done by normalisation of the signals using the cubic spline algorithm after background subtraction, and differentially regulated genes are defined by calculating the standard deviation differences of a given probe in a one-by-one comparison of samples or groups. Pathway analysis was done by using the Ingenuity Pathways Analysis software (version 5.5) from Ingenuity Systems (Redwood City, CA, USA).

Real-time RT-PCR: The experiment was done on the Roche LC480 using ABgene Mastermix "CM 215-A" and Roche Universal Probe Library. Oligos were designed using Roche 
ProbeFinder Webservice (https://qpcr2.probefinder.com/organism.jsp) and were synthesised by MWG. Two versions were designed per gene. All variants analysed span an intron to prevent cross reactions with possible genomic DNA contaminations.

Total reaction volume was $10 \mu \mathrm{L}$. We used $400 \mathrm{nM}$ final oligo concentration each, 100 $\mathrm{nM}$ final probe concentration and $6.3 \mathrm{ng}$ RNA (transcribed in cDNA using Superscript) per reaction. We used transcribed cDNA from RNA obtained from untreated cells or cells treated with dicentrine at the $50 \%$ inhibition dose $\left(\mathrm{IC}_{50}\right)$. No DNAse digest was done. Genes identified by microarray analyses were exemplarily analysed for validation by means of realtime RT-PCR (CDKN1A, E2F1). The housekeeping genes, HPRT1, G6PD, ALAS1, and $H M B S$, served as reference. The primer sequences are shown in Table 1.

All measurements are done in triplicates to calculate mean values and standard deviations. To calculate normalised mRNA expression values, we measured the sample's crossing point (expressed as a cycle number), the efficiency of the reaction, and the number of cycles completed to determine how much the DNA concentration must have increased for each sample by the end of the amplification. The analysis used these calculations to compare samples and to generate ratios as indicated by the manufacturer (Roche, Penzberg, Germany). The final ratio resulting from the calibrator-normalised relative quantification was a function of PCR efficiency and of the determined crossing points. The "concentration ratio" was determined as ratio of the target and the reference genes in the specific sample. To calculate the change of expression between untreated (calibrator) and dicentrine-treated samples, the concentration ratios of the sample was divided by the concentration ratio of the calibrator. This value is the "normalised ratio".

\section{Results}

Cytotoxicity of dicentrine: Transduced and non-transduced U87MG glioblastoma cell lines were treated with different concentrations of dicentrine and subjected to the XTT assay. The dose response curves are shown in Figure 1 and the $50 \%$ inhibition concentrations $\left(\mathrm{IC}_{50}\right)$ calculated from the dose response curves in Table $\mathbf{I}$. The $\mathrm{IC}_{50}$ value for dicentrine was 4.13to 9.09-fold higher in non-transduced U87MG cells $(43.0 \pm 4.44 \mu \mathrm{M})$ as compared to the three transduced cell lines. U87MG. $\triangle$ EGFR cells transduced with a deletion-activated EGFR expression vector were most sensitive towards dicentrine $(4.73 \pm 0.294 \mu \mathrm{M})$. The $\mathrm{IC}_{50}$ value of U87MG.DK-2N cells carrying a point mutation in the tyrosine kinase domain of EGFR was $8.69 \pm 0.09 \mu \mathrm{M}$, and the $\mathrm{IC}_{50}$ for U87MG.wtEGFR-2N was $10.4 \pm 0.48 \mu \mathrm{M}$. 
Differential gene regulation upon dicentrine treatment: Next, we were interested, whether specific mRNA expression profiles underlie the different $\mathrm{IC}_{50}$ values. Therefore, we performed microarray-based mRNA hybridisations. An overview of the number of up- or down-regulated genes upon treatment of the different U87MG cell lines with dicentrine is given in Figure 2 and Supplementary Table I . While the majority of differentially regulated genes were different between the different cell lines, 8 genes were commonly regulated in U87MG and U87MG.wtEGFR-2N cells, 10 genes in U87MG and U87MG.AEGFR, and 37 genes in U87MG and U87MG.DK-2N cells.

The non-intersected or the uniquely regulated genes for dicentrine were considered as those molecular players that are responsible as mechanism of action for this compound. The variability in the number of such uniquely regulated genes in different EGFR-transduced cell lines suggested the diverse pathways activated by individual compounds to elicit their cellular effects.

In order to see, whether dicentrine elicits its activity through one or several pathways, we investigated which signalling pathways were affected by the action of dicentrine in U87MG. $\triangle$ EGFR cells. For this reason, we analyzed all genes included in the Illumina biochip by means of the Ingenuity Pathway Analysis software. Out of $>80$ canonical pathways, five were significantly regulated upon dicentrine treatment $(P<0.05)$. The 10 functional groups of genes with the lowest P-values are shown in Figure 3. Of them, genes involved in BRCA1mediated DNA damage response were the most prominent. Based on this result, we then asked which genes were affected upon dicentrine treatment. The genes associated with BRCA1-mediated DNA damage response are shown in Figure 4.

In addition to BRCA1-mediated DNA damage response, other pathways, which appeared in dicentrine-treated U87MG. EGFR but not in non-transduced U87MG cells, were the aryl hydrocarbon receptor (AHR) signalling route, the G1/S as well as the G2/M cell cycle checkpoint regulation routes, and the p53 signalling pathway (Figure 3). All of these pathways are related to DNA damage.

Validation of microarray data by real-time RT-PCR: The results of DNA microarray hybridisations were exemplarily validated by real-time RT-PCR. For this purpose, two genes were chosen. One gene $(C D K N 1 A)$ was found to be up-regulated, another one $(E 2 F 1)$ was down-regulated upon dicentrine treatment in microarray analyses. As can be seen in Table II, corresponding up- or down-regulation of these genes after dicentrine treatment was also observed by real-time RT-PCR. 
Cell cycle and apoptosis parameters: To analyze the role of cell cycle and apoptosis for response of tumor cells towards dicentrine in a general context, we correlated the $\mathrm{IC}_{50}$ values for dicentrine of the tumor cell line panel of the Developmental Therapeutics Program of the National Cancer Institute, U.S.A., with the cell doubling times of the cell lines and the microarray-based mRNA expression of genes involved in cell cycle and apoptosis (http://dtp.nci.nih.gov). As shown in Table III, the $\mathrm{IC}_{50}$ values for dicentrine significantly correlated with the cell doubling times of the cell lines. The mRNA expression of CCNE1 and $C C N F$ and the proliferation-related genes, $P A K 4$ and $V E G F B$ were also significantly associated with the $\mathrm{IC}_{50}$ values for dicentrine. Other cyclins did not correlate with dicentrine. Furthermore, we analyzed apoptosis-related genes and found significant relationships between the expression of $C A S P-7, N F K B 1, P D C D 4$, and $D A P K 1$ to the $\mathrm{IC}_{50}$ values for dicentrine (Table III). An inverse correlation with borderline significance $(P=0.07)$ was observed for the NFkB-inhibitor, $I K B$. Other caspases as well as bcl-2 family members (bcl-2, bax, bcl-x, bxl-xL, and bad) did not correlate with response of tumor cell lines towards dicentrine.

\section{Discussion}

In the present investigation, we found a preferential cytotoxicity of dicentrine towards U87MG. $\triangle E$ EFR transduced with a constitutively deletion-activated EGFR expression vector as compared to non-transduced wild-type U87MG cells. A possible explanation for preferential cytotoxicity of dicentrine towards EGFR-overexpressing cells is that dicentrine binds to EGFR receptor. Hence, EGFR-expressing cells are killed, while non-EGFRexpressing cells survive. A mean energy of docking of $-8.1 \mathrm{kcal} / \mathrm{mole}$ and a $\mathrm{pKi}$ of $4.25 \mathrm{nM}$ have been calculated in silico by 3D molecular docking of dicentrine to the three-dimensional structure of the binding site of the EGFR tyrosine kinase, erlotinib, at the ATP-binding site of EGFR [26]. Based on this result, we have started the present investigation. The preferential cytotoxicity of dicentrine in EGFR-transfected cells found by XTT assays support the view that dicentrine inhibits EGFR-expressing cells by binding to EGFR.

The preferential activity of dicentrine towards U87MG. $\triangle$ EGFR cells was indeed EGFR-specific, since we and others found that this cell line exhibited resistance rather than sensitivity towards other DNA damaging agents such as cisplatin or artesunate [27, 28]. Anticancer with other modes of action (paclitaxel, vincristine, homoharringtonine, L-alanosine) were also less active in U87MG. EGFR cells $[29,30]$. Comparable data have been resported by other authors in other EGFR-expressing cells [31].

This preferential cytotoxicity was accompanied with an activation of BRCA1mediated DNA damage response, p53 signalling, G1/S and G2/M cell cycle regulation, and aryl hydrocarbon receptor pathways. The activation of these signalling routes might be explained by the fact that dicentrine intercalates DNA and induces DNA strand break by inhibition of DNA topoisomerases. The cell cycle might be arrested by dicentrine-induced DNA lesions.

Indeed, an association of dicentrine with DNA damage has previously been reported. Dicentrine intercalates DNA and inhibits DNA topoisomerases I and II [19, 32]. In this respect, dicentrine may be compared with classical anti-cancer drugs such as anthracyclines. The interrelationship of EGFR and BCRA1 has not well been investigated [33]. 
There are hints that EGFR inhibits the catalytic and DNA-cleaving activity of DNA topoisomerase II $[34,35]$. Furthermore, inhibition of EGFR by small molecule inhibitors such as gefitinib resulted in synergistic interaction with the DNA topoisomerase inhibitor, irinotecan [36]. The sensitivity of BRCA1- and BRCA2-deficient etoposide-induced DNA double strand breaks was mediated by DNA topoisomerase II [37], indicating a mechanistic relationship between both proteins. Although incompletely understood at present, it is worth speculating that EGFR cross-talks with DNA toposiomerases and BRCA1-mediated DNA damage response pathways. This cross-talk may be important for intercalation and DNA topoisomerase-mediated DNA damage of dicentrine.

Apart from the BRCA1-mediated DNA damage response pathway, other signalling routes were also differentially regulated between U87MG. $\triangle$ EGFR and parental U87MG cells. Among them were two signalling routes for arrest in G1/S or G2/M cell cycle phases. There is a plethora of investigations pointing to the eminent role of cell cycle arrest for cancer therapy. Cancer cells arresting in one of these phases can resist the detrimental effects of cancer chemotherapy $[38,39]$. On the other side, compounds capable to release arrested cells such as caffeine lead to a re-sensitization of cancer cells towards chemotherapy [40]. The fact that dicentrine differentially affects signalling routes for G1/S or G2/M arrest in U87MG and U87MG.AEGFR cells indicates that dicentrine interferes with cell cycle of cancer cells, possibly via the induction of DNA lesions.

The p53 signalling pathway was also activated in U87MG.AEGFR cells upon challenge with dicentrine. It is well known that p53 is activated by DNA lesions, either spontaneously occurring due to the tumour suppressor function of p53 or upon chemotherapeutic treatment. In both cases, p53 can mediate cell cycle arrest, DNA repair, and/or apoptosis. We conclude that the results obtained by microarray hybridisations may point to dicentrine-induced DNA lesions, as already been found by others [19, 32, 41].

This point of view is also conceivable with the finding that the aryl hydrocarbon receptor (AhR) signalling pathway was involved in the action of dicentrine. This signalling pathway is of enormous relevance in carcinogenesis, but also for resistance towards chemotherapy. Induction of the $m d r l$ gene, which is well-known to induce multidrug resistance, requires the AhR nuclear translocator [42]. Down-regulation of AhR repressor conferred resistance to apoptotic signals [43] and 17- $\beta$-estradiol-induced AhR overexpression with the characteristic phenotype of increased proliferation and resistance to apoptosis [44]. Given the general role of AhR for drug resistance, it is worth hypothesising 
that AhR may also be involved in response of tumour cells to dicentrine, as indicated by the results of the present investigation.

CDKN1A (p21, Cip1) appeared as one of the differentially expressed genes upon dicentrine treatment in our microarray experiments. This gene encodes a cyclin-dependent kinase inhibitor, which blocks cell cycle progression at the G1 phase by interacting with cyclin E. Interestingly, CCNE1 (cyclin E1) was one of the genes which significantly correlated with response of the N.C.I. cell line panel to dicentrine. This indicates that cell cycle progression may be inhibited by CDKN1A-cyclin $\mathrm{E}$ interaction upon dicentrineinducesd DNA damage.

It should be taken into account that dicentrine as many other natural compounds alike targets many cellular structures in the organism and is not cancer-specific in its bioactivity spectrum. Besides its cytotoxic activity, dicentrine inhibited trypanosomes [15]. Dicentrine is a known inhibitor of $\alpha$-adrenoreceptors [45-48]. It reduced hypertension and hyperlipidemia, two of the major risk factors for cardiovascular disease [49]. Electrophysiological examination of dicentrine on the conduction system of rabbit hearts showed that dicentrine exerted anti-arrhythmic action [50]. Dicentrine had beneficial effects on the rigidity of head and body circulation. It improved tube distensibility and wave transmission time [51]. Furthermore, dicentrine inhibited sodium and potassium channels [52] and thromboxane formation during platelet aggregation [53]. It also exerted chromosomal damaging clastrogenic effects [41].

If dicentrine will be further developed for cancer treatment, derivatives with preferential activity towards cancer cells and fewer side effects on other tissues and cellular targets should be generated. Dicentrine represents an example of a natural product with multitarget activity. It is valuable as lead compound for the derivatisation of second generation compounds with improved pharmacological features.

In conclusion, the data of the present investigation imply that otherwise drug-resistant tumours with constitutive activation and/or over-expression of EGFR may be preferentially susceptible towards dicentrine due to inhibition of EGFR and regulation of EGFR-related downstream signalling pathways.

Acknowledgement: This work has been supported by a grant of the Dietmar HoppFoundation (St. Leon-Rot, Germany). 


\section{References}

1. Volm M, Kästel M, Mattern J, Efferth T. Expression of resistance factors (P-glycoprotein, glutathione S-transferase-pi, and topoisomerase II) and their interrelationship to protooncogene products in renal cell carcinomas. Cancer 1993; 71: 3981-3987.

2. Konkimalla VB, Suhas VL, Chandra NR, Gebhart E, Efferth T. Diagnosis and therapy of oral squamous cell carcinoma. Expert Rev Anticancer Ther 2007; 7: 317-329.

3. Hirsch FR, Varella-Garcia M, Cappuzzo F. Predctive value of EGFR and HER2 overexpression in advanced non-small cell lung cancer. Oncogene 2009; 28 Suppl 1: S32S37.

4. Lemaire F, Millon R, Young J, Cromer A, Wasylyk C, Schultz I et al. Differential expression profiling of head and neck squamous cell carcinoma (HNSCC). Br J Cancer 2003; 89: 1940-1949.

5. Oliveira S, van Bergen en Henegouwen PM, Storm G, Schiffelers RM. Molecular biology of epidermal growth factor receptor inhibition for cancer therapy. Expert Opin Biol Ther 2006; 6: 605-617.

6. Astsaturov I, Cohen RB, Harari P. Targeting epidermal growth factor receptor signaling in the treatment of head and neck cancer. Expert Rev Anticancer Ther 2006; 6: 1179-1193.

7. Perea S, Hidalgo M. Predictors of sensitivity and resistance to epidermal growth factor receptor inhibitors. Clin Lung Cancer 2004; 6 Suppl 1: S30-S34.

8. Lalezari I, Shafiee A, Mahjour M. Major alkaloids of Glaucium flavum Grantz, population Ghom. J Pharm Sci 1976; 65: 923-924.

9. Shafiee A, Lalezari I, Rahimi O. Alkaloids of papaver genus IX. Alkaloids of Glaucium vitellinum Boiss and Buhse, population Seerjan and Glaucium pulchrum Stapf, population Elika. Lloydia 1977; 40: 352-355.

10. Shafiee A, Lalezari I, Lajevardi S, Khalafi F. Alkaloids of Glaucium flavum Grantz, populations Isfahan and Kazerun. J Pharm Sci 1977; 66: 873-874.

11. Vecchietti V, Casagrande C, Ferrari G. Alkaloids of Ocotea brachybotra. Farmaco Sci 1977; 32: 767-769.

12. Vecchietti V, Casagrande C, Ferrari G, Severini Ricca G. New aporphine alkaloids of Ocotea minarum. Farmaco Sci 1979; 34: 829-840.

13. Chen CC, Huang YL, Ou JC, Su MJ, Yu SM, Teng CM. Bioactive principles from the roots of Lindera megaphylla. Planta Med 1991; 57: 406-408.

14. Stévigny C, Block S, De Pauw-Gillet MC, de Hoffmann E, Llabrès G, Adjakidjé V, Quetin-Leclercq J. Cytotoxic aporphine alkaloids from Cassytha filiformis. Planta Med 2002; 68: 1042-1044. 
15. Hoet S, Stévigny C, Block S, Opperdoes F, Colson P, Baldeyrou B, Lansiaux A et al. Alkaloids from Cassytha filiformis and related aporphines: antitrypanosomal activity, cytotoxicity, and interaction with DNA and topoisomerases. Planta Med 2004; 70: 407-413.

16. Tzeng CC, Wu YC, Su TL, Watanabe KA, Lu ST, Chou TC. Inhibitory effects of isoquinoline-type alkaloids on leukemic cell growth and macromolecule biosynthesis. Gaoxiong Yi Xue Ke Xue Za Zhi 1990; 6: 58-65.

17. Kondo Y, Imai Y, Hojo H, Endo T, Nozoe S. Suppression of tumor cell growth and mitogen response by aporphine alkaloids, dicentrine, glaucine, corydine, and apomorphine. $\mathrm{J}$ Phartmacobiodyn 1990; 13: 426-431.

18. Huang RL, Chen CC, Huang YL, Ou JC, Hu CP, Chen CF, Chang C. Anti-tumor effects of d-dicentrine from the root of Lindera megaphylla. Planta Med 1998; 64: 212-215.

19. Woo SH, Sun NJ, Cassady JM, Snapka RM. Topoisomerase II inhibition by aporphine alkaloids. Biochem Pharmacol 1999; 57: 1141-1145.

20. Stévigny C, Bailly C, Quetin-Leclercq J. Cytotoxic and antitumor potentialities of aporphinoid alkaloids. Curr Med Chem Anticancer Agents 2005; 5: 173-182.

21. Huang HS, Nagane M, Klingbeil CK, Lin H, Nishikawa R, Ji XD et al. The enhanced tumorigenic activity of a mutant epidermal growth factor receptor common in human cancers is mediated by threshold levels of constitutive tyrosine phosphorylation and unattenuated signaling. J Biol Chem 1997; 272: 2927-2935.

22. Nagane M, Coufal F, Lin H, Bögler O, Cavenee WK, Huang HJ. A common mutant epidermal growth factor receptor confers enhanced tumorigenicity on human glioblastoma cells by increasing proliferation and reducing apoptosis. Cancer Res 1996; 56: 5079-5086.

23. Scudiero DA, Shoemaker RH, Paull KD, Monks A, Tierney S, Nofziger TH et al. Evaluation of a soluble tetrazolium/formazan assay for cell growth and drug sensitivity using human and other tumor cell lines. Cancer Res 1988; 48: 4827-4833.

24. Konkimalla VB, Blunder M, Korn B, Soomro SA, Jansen H, Chang W, Posner GH, Bauer $\mathrm{R}$, Efferth T. Effect of artemisinins and other endoperoxides on nitric oxide-related signaling pathway in RAW 264.7 mouse macrophage cells. Nitric Oxide 2008; 19: 184-191.

25. Eberwine J, Yeh H, Miyashiro K, Cao Y, Nair S, Finnell R et al. Analysis of gene expression in single live neurons. Proc Natl Acad Sci USA 1992; 89: 3010-3014.

26. Konkimalla VB, Suhas VL, Chandra NR, Gebhart E, Efferth T. Diagnosis and therapy of oral squamous cell carcinoma. Expert Rev Anticancer Ther 2007;7:317-329.

27. Nagane M, Levitzki A, Gazit A, Cavenee WK, and Huang HJ. Drug resistance of human glioblastoma cells conferred by tumor-specific mutant epidermal growth factor receptor through modulation of Bcl-XL and caspase-3 like proteases. Proc Natl Acad Sci USA 1998;95:5724-5729. 
28. Efferth T, Sauerbrey A, Olbrich A, Gebhart E, Rauch P, Weber HO et al. Molecular modes of action of artesunate in tumor cell lines. Mol Pharmacol 2003;64:382-394.

29. Efferth T, Gebhart E, Ross DD, Sauerbrey A. Identification of gene expression profiles predicting tumor cell response to L-alanosine. Biochem Pharmacol 2003;66:613-621.

30. Efferth T, Sauerbrey A, Halatsch ME, Ross DD, Gebhart E. Molecular modes of action of cephalotaxine and homoharringtonine from the coniferous tree Cephalotaxus hainanensis in human tumor cell lines. Naunyn Schmiedebergs Arch Pharmacol 2003;367:56-67.

31. Wosikowski K, Schuurhuis D, Kops GJ, Saceda M, and Bates SE. Altered gene expression in drug-resistant human breast cancer cells. Clin Cancer Res 1997;3:2405-2414.

32. Zhou BN, Johnson RK, Mattern MR, Wang X, Hecht SM, Beck HT et al. Isolation and biochemical characterization of a new topoisomerase I inhibitor from Ocotea leucoxylon. J Nat Prod 2000; 63: 217-221.

33. Marks JL. EGFR mutant lung adenocarcinomas in patients with germline BRCA mutations. J Thoracic Oncol 2008; 3: 805.

34. Markovits J, Larsen AK, Ségal-Bendirdjian E, Fossé P, Saucier JM, Gazit A et al. Inhibition of DNA topoisomerases I and II and induction of apoptosis by erbstatin and tyrphostin derivatives. Biochem Pharmacol 1994; 48: 549-560.

35. Allen GC, Lubas S, Wax MK, Devore RF 3rd. Epidermal growth factor regulates topoisomerase II activity and drug sensitivity in human KB cells. Otolaryngol Head Neck Surg 1996; 114: 785-792.

36. Koizumi F, Kanzawa F, Ueda Y, Koh Y, Tsukiyama S, Taguchi F et al. Synergistic interaction between the EGFR tyrosine kinase inhibitor gefitinib ("Iressa") and the DNA topoisomerase I inhibitor CPT-11 (irinotecan) in human colorectal cancer cells. Int J Cancer 2004; 108: 464-472.

37. Treszezamsky AD, Kachnic LA, Feng Z, Zhang J, Tokadjian C, Powell SN. BRCA1- and BRCA2-deficient cells are sensitive to etoposide-induced DNA double-strand breaks via topoisomerase II. Cancer Res 2007; 67: 7078-7081.

38. Efferth T, Fabry U, Osieka R. Apoptosis and resistance to daunorubicin in human leukemic cells. Leukemia 1997; 11: 1180-1186.

39. Johansson M, Persson JL. Cancer therapy: targeting cell cycle regulators. Anticancer Agents Med Chem 2008; 8: 723-731.

40. Efferth T, Fabry U, Glatte P, Osieka R. Expression of apoptosis-related oncoproteins and modulation of apoptosis by caffeine in human leukemic cells. J Cancer Res Clin Oncol 1995; 121: 648-656.

41. Tadaki S, Nozaka T, Yamada S, Ishino M, Morimoto I, Tanaka A, Kunitomo J. Clastogenicity of aporphine alkaloids in vitro. J Pharmacobiodyn 1992; 15: 501-512. 
42. Wong PS, Li W, Vogel CF, Matsumura F. Charcterization of MCF mammary epithelial cells overexpressing the Arylhydrocarbon receptor (AhR). BMC Cancer 2009; 9: 234.

43. Zudaire E, Cuesta N, Murty V, Woodson K, Adams L, Gonzalez N et al. The aryl hydrocarbon receptor repressor is a putative tumor suppressor gene in multiple human cancers. J Clin Invest 2008; 118: 640-650.

44. Mathieu MC, Lapierre I, Brault K, Raymond M. Aromatic hydrocarbon receptor (AhR).AhR nuclear translocator- and p53-mediated induction of the murine multidrug resistance mdr1 gene by 3-methylcholanthrene and benzo(a)pyrene in hepatoma cells. J Biol Chem 2001; 276: 4819-4827.

45. Teng CM, Yu SM, Ko FN, Chen CC, Huang YL, Huang TF. Dicentrine, a natural vascular alpha 1-adrenoceptor antagonist, isolated from Lindera megaphylla. Br J Pharmacol 1991; 104: 651-656.

46. Yu SM, Hsu SY, Ko FN, Chen CC, Huang YL, Huang TF, Teng CM. Haemodynamic effects of dicentrine, a novel alpha 1-adrenoceptor antagonist: comparison with prazosin in spontaneously hypertensive and normotensive Wistar-Kyoto rats. Br J Pharmacol 1992; 106 : 797-801.

47. Yu SM, Ko FN, Chueh SC, Chen J, Chen SC, Chen CC, Teng CM. Effects of dicentrine, a novel alpha 1-adrenoceptor antagonist, on human hyperplastic prostates. Eur J Pharmacol 1994; 252: 29-34.

48. Mustafa MR, Achike FI. Dicentrine is preferentially antagonistic to rat aortic than splenic alpha 1-adrenoreceptor stimulation. Acta Pharmacol Sin 2000; 21: 1165-1168.

49. Yu SM, Kang YF, Chen CC, Teng CM. Effects of dicentrine on haemodynamic, plasma lipid, lipoprotein level and vascular reactivity in hyperlipidaemic rats. Br J Pharmacol 1993; 108: 1055-1061.

50. Young ML, Su MJ, Wu MH, Chen CC. The electrophysiological effects of dicentrine on the conduction system of rabbit heart. Br J Pharmacol 1994; 113: 69-76.

51. Chang KC, Lo HM, Lin FY, Tseng YZ, Ko FN, Teng CM. Effects of dicentrine on the mechanical properties of systemic arterial trees in dogs. J Cardiovasc Pharmacol 1995; 26: $169-76$.

52. Su MJ, Nieh YC, Huang HW, Chen CC. Dicentrine, an alpha-adrenoceptor antagonist with sodium and potassium channel blocking activities. Naunyn Schmiedebergs Arch Pharmacol 1994; 349: 42-49.

53. Yu SM, Chen CC, Ko FN, Huang YL, Huang TF, Teng CM. Dicentrine, a novel antiplatelet agent inhibiting thromboxane formation and increasing the cyclic AMP level of rabbit platelets. Biochem Pharmacol 1992; 43: 323-329. 


\section{Figure legends:}

Figure 1: Cytotoxicity towards dicentrine towards transduced and non-transduced U87MG cell lines as determined by the XTT assay. Dose response curves of two independent experiments are shown (Mean values and SEM of each four measurements).

Figure 2: Genes uniquely and commonly regulated in transduced and non-transduced U87MG cell lines. Venn diagram representation was chosen to compare overlaps of differentially expressed genes after dicentrine treatment.

Figure 3: Comparison of canonical pathway analysis for dicentrine-treated non-transduced U87MG and U87MG.AEGFR transduced with a deletion-activated EGFR expression vector. Each bar represents the ratio of the number of genes that are regulated in a particular pathway upon treatment with dicentrine $\left(\mathrm{IC}_{50}\right)$ for $72 \mathrm{~h}$. Only the top 10 canonical pathways are shown of U87MG (dark grey bars) and U87MG. $\mathrm{EGFR}$ (light grey bars) as analyzed by the Ingenuity Pathway Analysis software.

Figure 4: BRCA1-mediated DNA damage response pathway. This pathway was identified as top canonical pathway differentially regulated by dicentrine in U87MG and U87MG. $\mathrm{EEGFR}$ cells (see Figure 4). Genes in red colour indicate up-regulation, whereas genes in green colour indicate down-regulation of mRNA expression upon dicentrine treatment.

Supplementary Figure 1: Chemical structure of dicentrine 
Table I: $\mathrm{IC}_{50}$ values for dicentrine of different $\mathrm{U} 87 \mathrm{MG}$ cell lines and respective degrees of sensitisation to dicentrine of transduced cell lines in comparison to non-transduced cells. The $\mathrm{IC}_{50}$ values were calculated from the dose response curves shown in Figure 1.

\begin{tabular}{lcl} 
Cell line & $\begin{array}{c}\mathbf{I C}_{50} \text { Value } \\
(\boldsymbol{\mu M})\end{array}$ & $\begin{array}{c}\text { Degree of } \\
\text { sensitization }\end{array}$ \\
\hline U87MG & $43.0 \pm 4.44^{*}$ & ----- \\
U87MG. $\triangle$ EGFR & $4.73 \pm 0.29$ & $9.09^{* *}$ \\
U87MG.DK-2N & $8.69 \pm 0.09$ & 4.95 \\
U87MG.wtEGFR-2N & $10.4 \pm 0.48$ & 4.13 \\
\hline
\end{tabular}

* Mean SEM of two independent experiments with each four-fold determination

** $\mathrm{IC}_{50}$ of the corresponding cell line divided by $\mathrm{IC}_{50}$ of U87MG

Table II: Validation of mRNA microarray results

\begin{tabular}{clllll} 
Gene & Cell line & Method & Untreated cells & $\begin{array}{l}\text { Dicentrine- } \\
\text { treated cells }\end{array}$ & $\begin{array}{l}\text { Fold } \\
\text { change }\end{array}$ \\
\hline CDKN1A $^{\text {a) }}$ & U87MG & microarray & $10,604.6 \pm 310.6^{*}$ & $20,263.1 \pm 596.2$ & 1.7 \\
& & RT-PCR & $0.137 \pm 0.0832^{* *}$ & $0.533 \pm 0.0465$ & 3.89 \\
& U87MG. $\Delta$ EGFR & microarray & $7,846.0 \pm 197.1$ & $21,471.0 \pm 472.6$ & 2.7 \\
& & RT-PCR & $0.025 \pm 0.0013$ & $0.268 \pm 0.0094$ & 10.74 \\
& & & & \\
E2F1 ${ }^{\text {b) }}$ & \multirow{2}{*}{ U87MG } & microarray & $330.0 \pm 14.8$ & $150.0 \pm 5.1$ & -2.2 \\
& & RT-PCR & $0.003 \pm 0.0012$ & $0.001 \pm 0.0004$ & -3.21 \\
& U87MG. $\Delta$ EGFR & microarray & $505.3 \pm 18.1$ & $135.2 \pm 5.8$ & -3.7 \\
& & RT-PCR & $0.001 \pm 0.0001$ & $0.000 \pm 0.000$ & -3.77 \\
\hline
\end{tabular}

Genes were selected for real-time RT-PCR analysis from the list of differentially expressed genes.

a) Homo sapiens cyclin-dependent kinase inhibitor 1a (p21, Cip1) (CDKN1A), transcript variant 2

b) Homo sapiens E2F transcription factor (E2F1)

* average hybridization signal $( \pm$ SEM).

** Conc ratio ( \pm Conc ratio STD). 
Table III: Relationship between cell doubling times and microarray-based mRNA expression of cell cycle-, proliferation- or apoptosis-related genes to dicentrine in tumor cell lines of the N.C.I. drug screening panel (http://dtp.nci.nih.gov).

Symbol Name

Cell cyle and proliferation:

\section{--- Cell doubling time}

CCNE1

CCNF

$P A K 4$

VEGFB

\section{Apoptosis:}

CASP 7

NFKB1

$I K B$

PDCD4

$D A P K 1$ cyclin E1

cyclin $\mathrm{F}$

P21(CDKN1A)-activated kinase 4

vascular endothelial growth factor B

apoptosis-related cysteine peptidase

nuclear factor of kappa light polypeptide

gene enhancer in B-cells 1

inhibitor of NFKB

programmed cell death 4

(neoplastic transformation inhibitor)

death-associated protein kinase 1
$P$-Value (Fisher exact test)

0.0002

0.017

0.016

0.039

0.011

0.004

0.008

0.069

0.007

0.040 


\section{Graphical abstract}

Dicentrine exterts preferential cytotoxicity towards EGFR-transfectant U87MG cells. As determined by microarray habridisations, this was accompanied by activation of BRCA1, p53, AhR signalling and G1/S and G2/M cell cycle regulation.

Analysis: Observation 1

Observation $1 \quad$ Observation 2

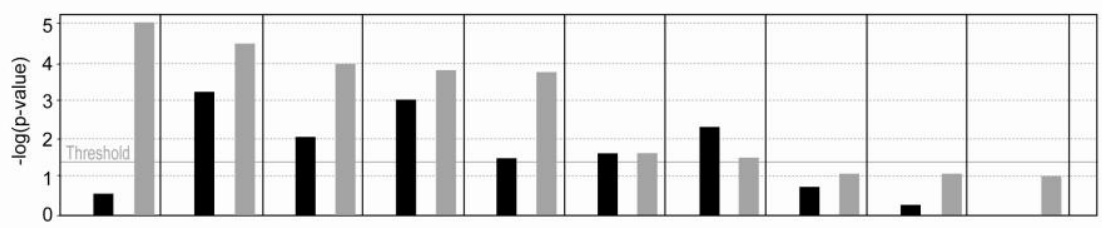

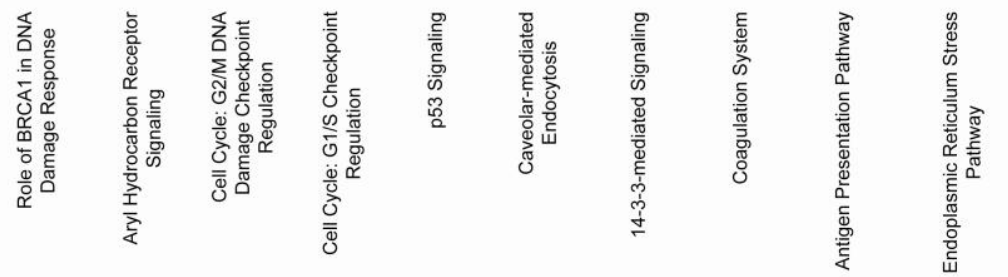



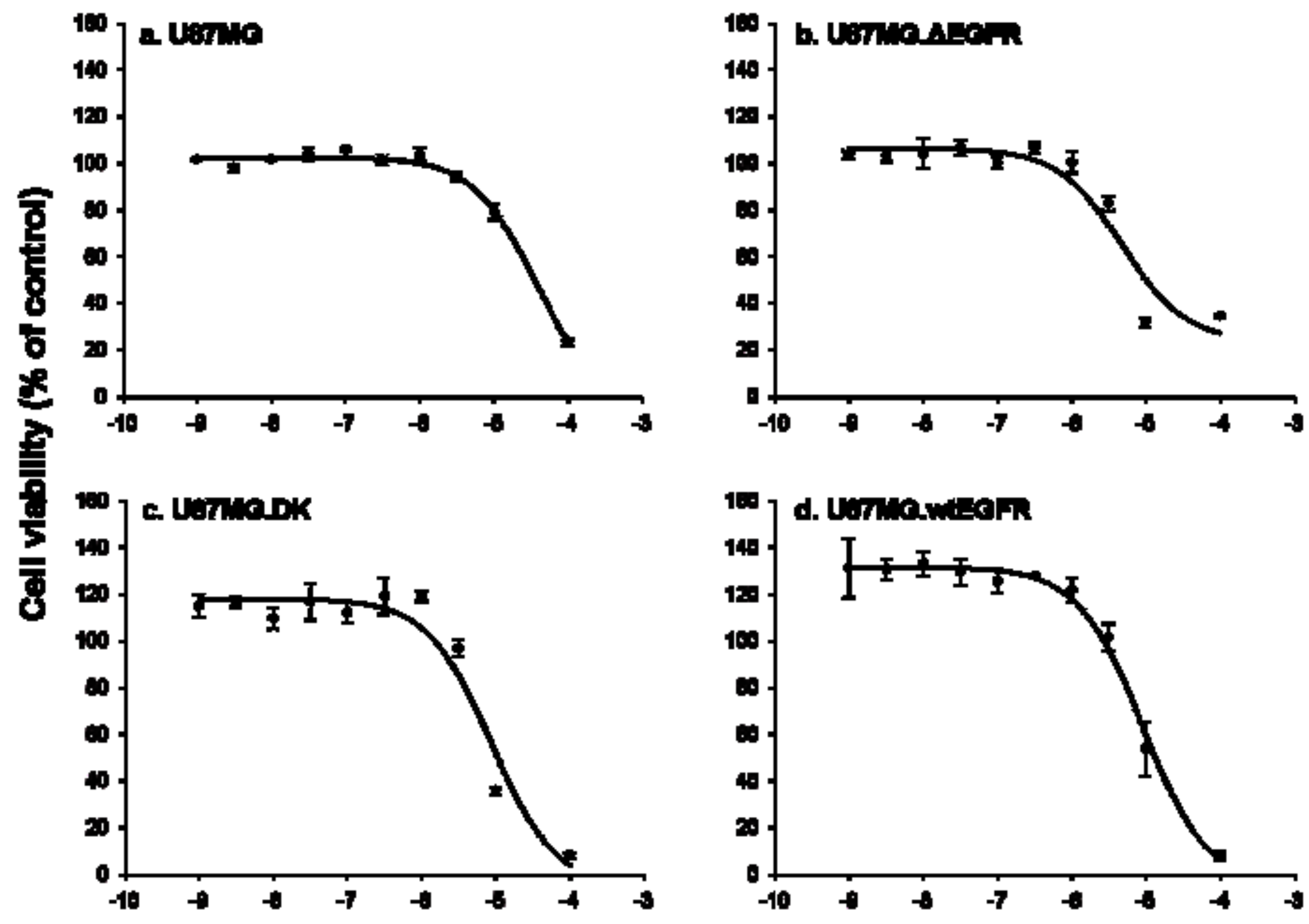

Conowitration (log M) 


\section{Dicentrine}

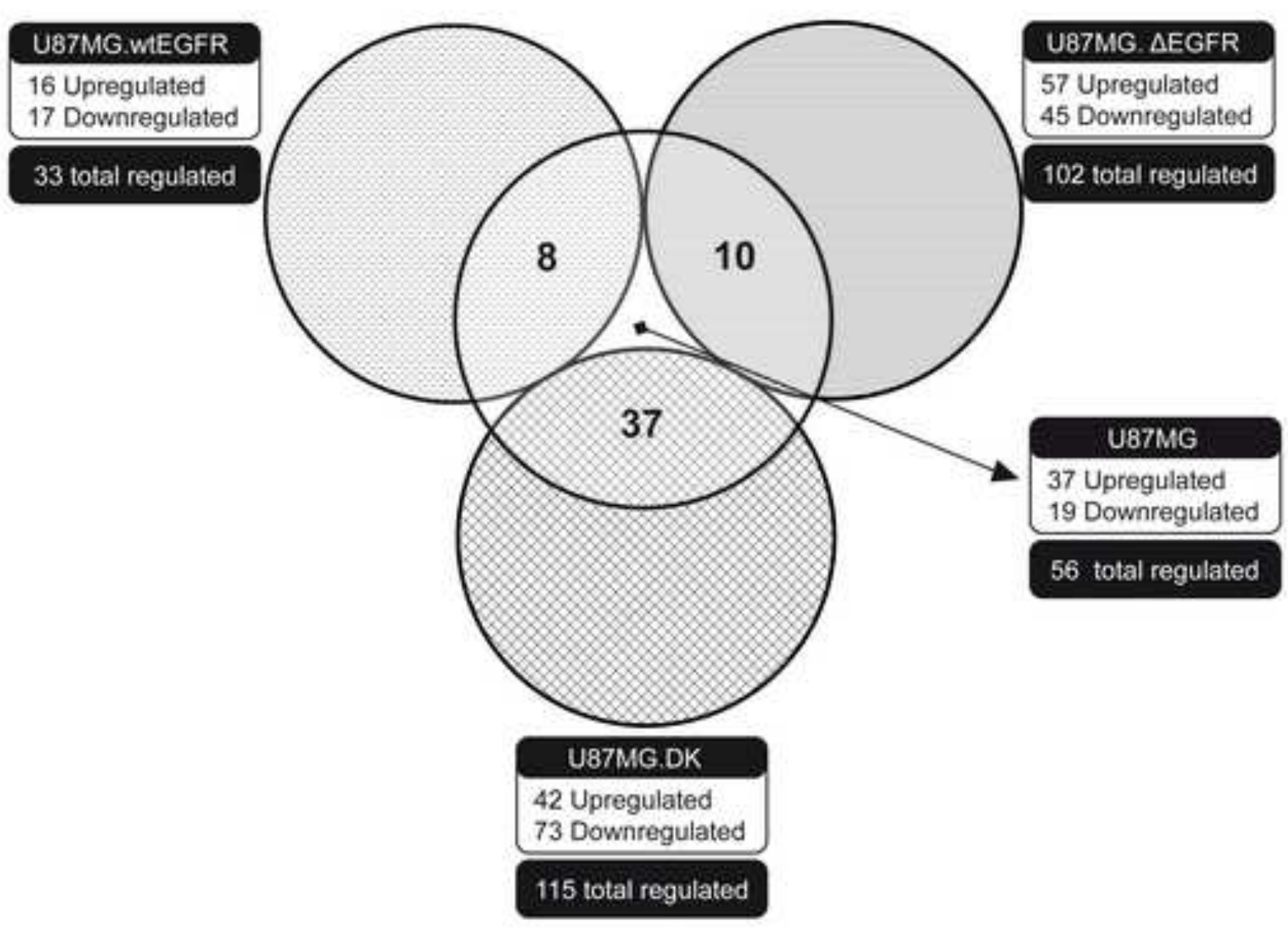

DIC treatment in different cell lines 
Analysis: Observation 1

- Observation 1 nobservation 2

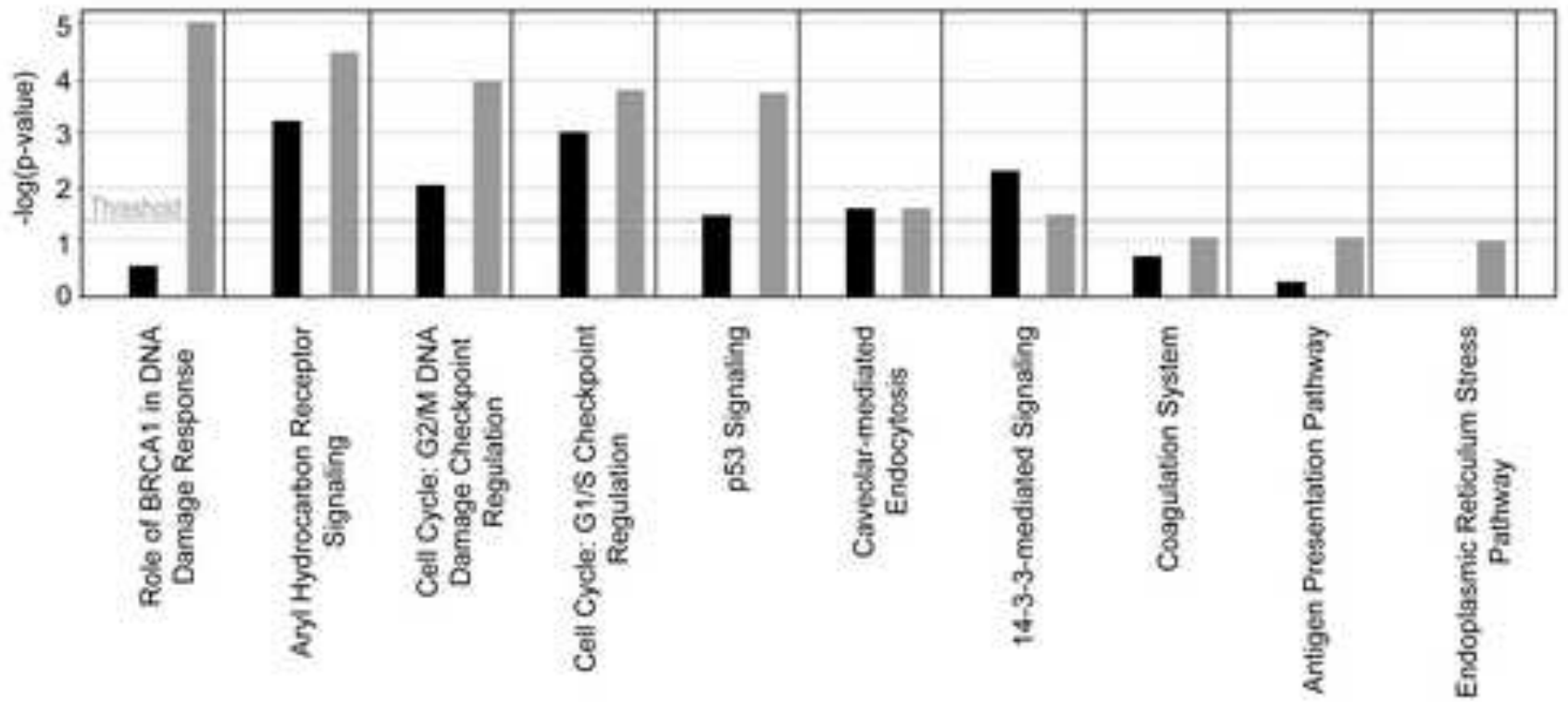




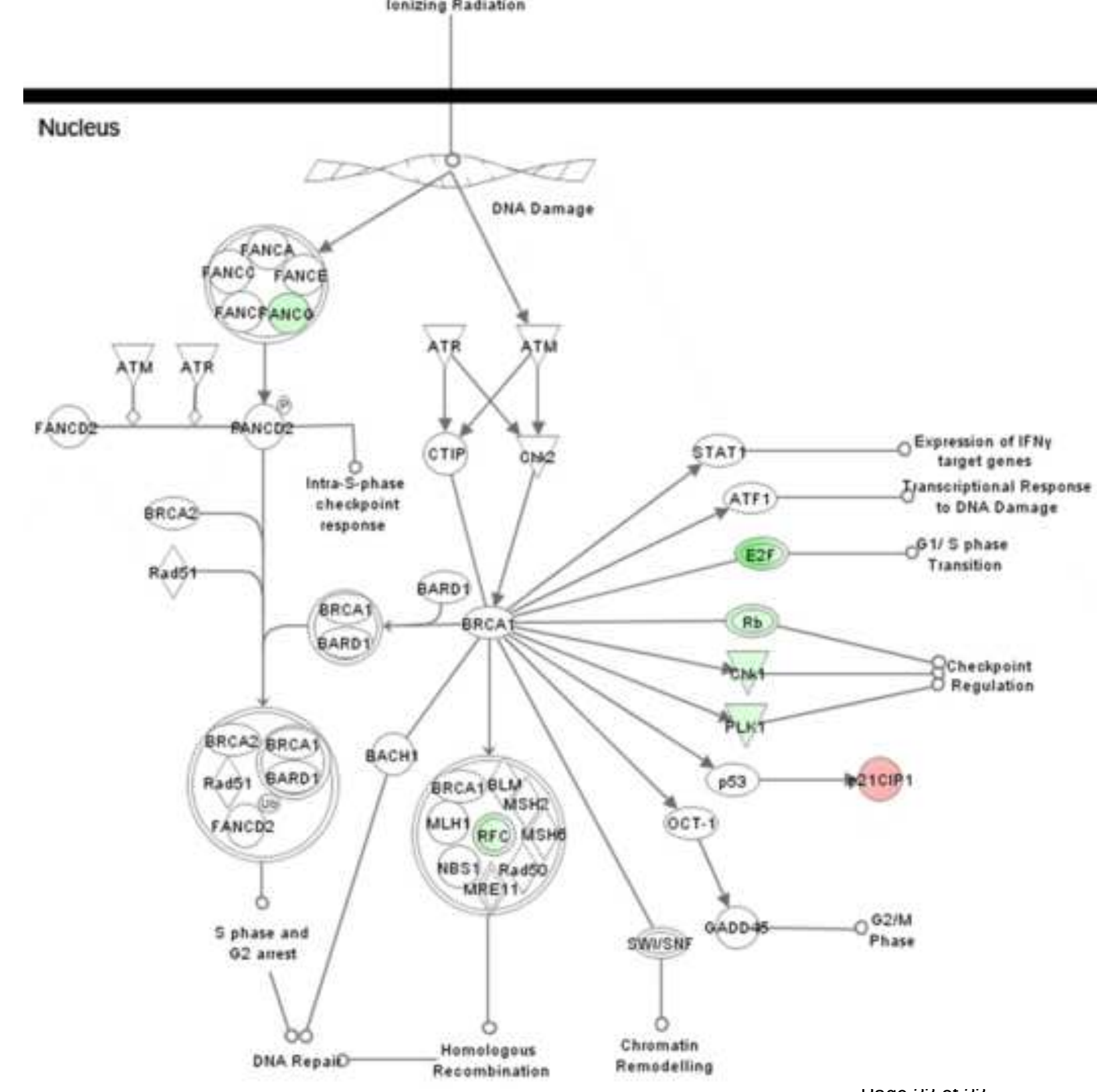

rage 23 or 23

rage 20 or 20 